\title{
Finding a Way
}

\section{Techniques to Avoid Schema Tension in Narrative Design Christy Dena}

Transactions of the Digital Games Research Association 2017, Vol. 3, No. 1, pp. 27-61

ISSN 2328-9414

http://todigra.org

TEXT: Licensed under Creative Commons Attribution (CC BYNC- ND 2.5) http://creativecommons.org/licenses/by-nc- nd/2.5/ IMAGES: All images appearing in this work are property of the respective copyright owners, and are not released into the Creative Commons. The respective owners reserve all rights.

\section{ABSTRACT}

Game designers and game writers do not have the same understandings, processes, or approaches, and this impedes good practice. This is not due to the two modes being so different or incompatible however, as has been claimed now and in earlier narratology and ludology debates. Instead, this article argues that incompatibilities are due more to the schemas of creation: the mental models we are taught and create with, that thwart more integrated practices. We learn to create and think about games in one way, and narrative in another. This siloing is due to a predictable differentiation rhetoric that occurs at the emergence of a new medium: games are not stories, games are not films, VR is not film, $\mathrm{X}$ is understood by not being Y. This arbitrariness of difference facilitates a schism in the creator's mind, where elements, roles and 


\section{ToDiGRA}

industries become irreconcilable. Indeed, whole swathes of wisdom are put to the side in an effort to be recognised as different. When narrative is used in games, then, developers rely on external design grammars, where models from other artforms are imported and shoehorned. There have been attempts to reduce such siloing, but integration cannot happen merely through recognising common elements or traits within a game object. Instead, this article argues that a common understanding can be found through the common factor of the audience or player. To illustrate this point, two successful audience/player-centered approaches from filmmaking and education are outlined, along with a tweaking of the successful MDA framework, providing structures for creatives to avoid the problem of design schema tension and create better projects.

\section{Keywords}

narrative design, game design, games writing, screenwriting, design schemas, serious games, narratology, ludology, learning design, games education, transmedia, cross-media.

\section{INTRODUCTION}

As a writer-designer who works with game developers, filmmakers, visual arts organisations, communities, corporations, and agencies, I am always looking for efficient interdisciplinary practices. As an industry and academic educator, I am always looking for ways I can help creatives avoid habits that can thwart great work. As a researcher, I am always looking for ways I can deepen, discuss, and share my discoveries. This article presents a perspective on a problem, and offers solutions for developers and educators alike to implement. The problem is the siloing of narrative and game elements, roles, and industries.

Developers who view narrative and game elements as separate (and perhaps even incompatible) produce games where they are experienced separately. For example: narrative is relegated to cut-scenes, text-laden 
diaries and pop-ups, and on-screen dialogue, and is often in conflict with the mechanics. Famously, the term "ludonarrative dissonance" was introduced by designer Clint Hocking to describe this occurrence, and it attests to the pervasiveness of this siloed thinking (Hocking 2007). Indeed, there is a relationship between how narrative designers, designers, and writers perceive the relationship between narrative and design, and the end-product.

To get around this, efforts to integrate narrative and game modes are often channeled into including writers during the beginning of development to have a voice in the decision-making. Indeed, an aphorism that I previously put forward to explain what facilitates best practice is, "early and equal.” (Fingleton, Dena, \& Wilson 2008, 63) The idea behind these approaches is to ensure the writers are not spending all their time retrospectively applying narrative elements to fixed gameplay, and therefore providing weak links between them or at worst perpetuating the dissonance between them. This has been called a "narrative wrapper" approach, which has been criticised by game writers such as Richard Dansky, who is the Central Clancy Writer for Ubisoft, for facilitating bad practice:

"And so when we talk about the "narrative wrapper" of a game, we're implicitly stating that the narrative is not of the game itself. It's something we're supposed to wrap around the gameplay to make it transportable and attractive, and keep the targeting reticule from dripping burger grease on our fingers, but it's ultimately unattached and disposable." (Dansky 2014)

A response to this issue is the emergence of the "narrative designer" role, where the relationship between writing and design is assigned to a person as a responsibility during development. For instance, Gameloft Entertainment Toronto Inc. describe the narrative designer role as someone who "works closely with a project's core design team at every step of the way to develop a strong symbiotic relationship between the game's mechanics, design, and structure, and the narrative/story being used to support and enhance that structure.” (Gameloft 2016) Likewise, the narrative designer for Crystal Dynamics, involves having 
to "[c]onceive scenarios, missions and objectives that are tied to larger story goals” (Crystal Dynamics 2016); Obsidian Entertainment's narrative designer needs to "[e]nsure game concepts and mechanics are appropriate to fiction and positioning" and "[c]ontribute to all aspects of game design” (Obsidian Entertainment 2016); and Supermassive Games' narrative designer needs "a superb understanding of story and the intersection of it with gameplay” (Supermassive Games 2017). These roles remind us there is a division of game and narrative elements, but now it is seen as necessity to undo that siloing.

My contention is that these difficulties have nothing to do with any socalled incompatibility of narrative and game elements, but instead are born from conflicting ways of thinking about narratives and games. They are divided in our minds and so do not easily blend. To understand how this could be the case, I draw on the theory of schemas. Introduced by cognitive psychologist Frederic Bartlett, schemas explain how we remember not just subject matter but how to categorise and apply them (Bartlett 1932). "A schema is a cognitive construct that organizes elements of information according to the manner with which they will be dealt.” (Sweller 1994) This is so we don't have to crowd our mind with details, and instead we classify experiences into retrievable bundles. If I need to ride a bike, I remember how all the actions go together rather than remember each individual step. I can then apply the same principle to exercise bikes, or use skiing to help me understand rollerblading for instance.

Story and game design schemas, then, are our ways of understanding stories and games. We learn them through experiencing actual stories and games, and as practitioners we also learn them through articles, books, workshops and consultations. I am not alone in holding this view. Schemas have been applied to design before. Donald Norman has spoken about "mental models," and how systems are designed according to the designer's mental model, while the user also has their mental model (Norman 1988). This is why we have usertesting and playtesting: to find where our mental models are not aligning. Game researchers Craig 
Lindley and Charlotte Sennersten also discuss "story" and "game play schemas" (original wording) from a player perspective, where the former is about patterns that make stories comprehensible, and the latter is about the orchestration of cognitive resources to generate motor outputs (Lindley and Sennersten 2006). So let's take a step back and look at why narrative and game schemas have developed as isolated and incompatible mental models, as this will help us understand not only how this happened (so it may be prevented from happening again), and to aid in determining a solution.

\section{CAUSES OF DESIGN SCHEMA TENSION}

Why is it that we have narrative and game design schema tension? What causes design schema tension? The obvious answer is that narrative design schemas were developed before game design schemas. Writing for theatre, novels, film and television has existed for longer than games (digital games specifically). So, game design schemas are understandably different to narrative design schemas. But the reverse is what should be true. It makes sense that game design would be heavily influenced by the processes and approaches of more mature artforms. But this is not the case and let us look at why. The following describes two key factors that contribute to the phenomenon of design schema tension in game design (and many artforms): differentiation rhetoric and external design grammars.

\section{Identity and Definition by Differentiation}

When a new area of interest emerges there are the inevitable stages of development as it moves from being an anomaly on the fringes to everyday. All artforms go through this process, electronic/video/digital games included. For example, recently we've seen this play out with VR, when Janet Murray declared it is "Not a Film and Not an Empathy Machine.” (Murray 2016) Semiotician Yuri Lotman observed this 


\section{ToDiGRA}

process, and explained it as an individuation process, with its primary mechanism being the boundary: "Every culture begins by dividing the world into 'its own' internal space and 'their' external space. How this binary division is interpreted depends on the typology of the culture." (Lotman 1990, 131) A culture, in other words, forms itself through binaries of inside and outside, us and them, good and bad.

As artforms become more pervasive, this process of boundary forming individuation manifests itself in differentiation rhetoric. We have this laid bare in the Narratology and Ludology debate in the late 90s and early 2000s. I won't duplicate the arguments here, but what emerged from that debate was an indisputable goal: the need to recognise and study game phenomena as a unique cultural form in itself. The debate successfully championed games being treated as a unique phenomenon that could not be understood through current frameworks and lenses. Indeed, it was common for ludologists and cultural theorists to jointly agree on their orientation against narratology.

While it meant better recognition and understanding amongst peers, this differentiated identity came at a cost. Game theorist and journalist Dan Golding, for instance, has reviewed the history of videogame scholarship and found the definition of games as configurable texts became the primary approach to understanding what games are for scholars and practitioners (Golding 2013). Golding continues, explaining how games became distinguished through theories such as Espen Aarseth's "configurative function" of "scriptons [that] are in part chosen or created by the user” (Aarseth 1997, 64); and Markku Eskelinen's “configurative practice" where games are "a combination of ends, means, rules, equipment, and manipulative action.” (Eskelinen 2001) Games became understood as different to the fixed texts of other artforms through the idea of games being configurable. To Golding, this "notion of configurability has had long-standing repercussions across a significant range of videogame scholarship.” (Golding 2013, 33) A definition through textual difference can cause harm. Indeed, as Brian Upton, Senior Game Designer at Sony Santa Monica, explains: "interactivity is 
a thing that games can DO. It is not what games ARE.” (Upton 2015b, original emphasis)

Indeed, by separating narrative and game modes as distinct phenomena, integrated use has been thwarted. We now have a siloing of game development roles, and ultimately, functions within a game. We have "ludonarrative dissonance," (Hocking 2007) we have "Aristotle versus Mario," and "Save the Cat" versus "Slay the Dragon.” (Bryant and Giglio 2015) There has been, in short, a splintering of narrative and game modes in the name of identity-forming. This happened in academia and industry, as a way to recognise and legitimize the area of interest. But if we look at this through an instructional designer lens, we can see two disparate mental models that developers then have to exert extra cognitive effort to mentally integrate. This is perhaps why this task is assigned to a person, the narrative designer, rather than everyone on the team. Indeed, one can see how this can affect existing developers, however, the question then arises, how are the next generation of narrative designers being taught?

\section{External Design Grammars}

How do game designers and game writers learn to do narrative design? The most well-known narrative and game schemas are taught by people who work with, and think in, one or the other. Developers learn about games from people who make digital games and/or tabletop games, and they learn about narrative from people who write films and TV (less so from novelists, and even less so from theatre despite congruence with performance). Developers looking to understand story go to the people who work in story, and vice versa. How does this phenomenon occur in textbooks?

There are key texts (among others) that show up on curriculums worldwide: Game Design Workshop (Fullerton 2008); The Art of Game Design (Schell 2010), On Game Design (Rollings and Adams 2003), and 


\section{ToDiGRA}

Rules of Play (Salen and Zimmerman 2003); and while each of them have differences in their discourse and framing, there are patterns in the citations. They do what most game, screen and novel-writing books do: reference three-act structures through Aristotle's Poetics (Aristotle 1997 [330BC]), Joseph Campbell's The Hero with a Thousand Faces (Campbell 2012 [1949]), and Christopher Vogler's development on Campbell's monomyth with The Writer's Journey (Vogler 2007).

A game-writing approach is then explained as being different through pathing structures. These are the nodal diagrams that explain how a player can access different parts of a story in different ways; a linear, strand-of-pearl structure or a branching structure for instance. Then to bring in the concept of the hero's journey, there is a repositioning of the hero's journey as the player's journey, a "first-person character arc." (Freeman 2004) Developer and educator Jesse Schell goes further, explaining that "[b]ecause so many videogames revolve around the theme of heroism, it is only logical that the hero's journey is a relevant structure for a powerful videogame story." (Schell 2010, 273) Famously, we've also seen how developer Jenova Chen applied this thinking to Journey (Chen 2013), along with other practitioners.

Indeed, students and some professional developers alike utilise these touchstone narrative structures during development. But as we have seen with the development of different types of games (Lazzaro 2004; Hartmann and Klimmt 2006; Kallio, Mäyrä, Kaipainen 2011; Hamari and Tuunanen 2014), heroism is not a universal desire for play, and further to that neither is playing a hero that initially refuses the call to help others.

But let's take a step back here and ask, why are such structures taught to game developers? Education researcher James Paul Gee has a helpful concept here: that of "internal" and "external design grammars." (Gee 2003) Similar to Lotman's binary of the internal and external, Gee refers specifically to the design grammars of individuals. Internal design grammars are "the principles and patterns in terms of which one can 
recognize what is and what is not acceptable or typical content in a semiotic domain." (ibid., 30) That is, can you identify what is typical and what is atypical? Can you identify a game in its design form? Can you identify problems in its early form? Do you know how to identify a typical and non-typical platformer in the design document stage, and are you able to identify issues the designers will face based on that document?

Whereas an external design grammar is understood as "the principles and patterns in terms of which one can recognize what is and what is not an acceptable or typical social practice and identity in regard to the affinity group associated with a semiotic domain.” (ibid.) Can you list all the key texts or works? Do you know the identities involved? Do you know what people value in the field? Do you know the social practices of the affinity group? Do you know facts about the domain? In this regard, a person with an external design grammar would be able to list the most well-known platformers, key auteurs or studios behind them, facts about them, and how fans communicate about them.

It is my uncontentious opinion that Aristotle, Campbell and Vogler are invoked by many games educators and developers because they have an external design grammar of narrative. They know the things that everyone else refers to, not what people who work in the field have found to be fruitful. This is not to claim that it is only game developers who refer to these structures, they certainly aren't. But there are other approaches screenwriters are aware of that have proven more helpful in their attempt to create better works. Their insights, however, could only be accessed by those with an internal design grammar-someone with a narrative schema.

So we have external design grammars and differentiation rhetoric, both working to create and maintain a design schema tension. We have seen the consequences of this in practice with both the cognitive effort required to integrate these disparate approaches, and the wrapping and 


\section{ToDiGRA}

shoehorning that is done to make these elements reach some kind of gestalt (or not) within a game. How do we resolve these tensions?

\section{ATTEMPTING TO HEAL THE RIFT}

In this section I will talk about what is happening already to heal the rift and what I propose to propel this process further. The "narrative designer" role is an attempt to address this issue, but as mentioned previously, it places the task of integration into the hands of a person and maintains the schemas they are trying to integrate in the first place. It is a promising but temporary solution that does not get to the heart of the problem. Another approach is one explored by narrative and game theorists, where they seek to view games as having elements that are shared with other artforms, both narrative and game-based. It is a transmodal approach where narrative and game elements are analysed across media to reveal the congruences and differences (Frasca 1999; Juul 2001; Frasca 2003; Eskelinen 2005; Ryan 2006; Dena 2009). Games and films, for instance, both have characters and settings. We all need to create characters, we all need to create settings. There are some aspects that stay the same across media, and some that are different. By recognising that we have similar elements that instantiate in different ways, we can conceptually bring them together. Indeed, the "cognitive effort required to mentally integrate disparate sources of information can be reduced or eliminated by physically integrating the various entities." (Sweller 1994, 302)

A more recent proposal is a "ludonarrative toolbox" that aims to provide "a common ground for game designers and academics to discuss the relationship between ludocity and narrativity.” (Koenitz et al. 2015) In this approach, practitioners are offered an evaluative lens to help situate what they're doing through semantic differentials: is it canon or not, scripted or procedural, in the author's or the player's control? In all of these transmodal approaches there is a focus on setting, props, objects, and characters, or on traits. The theorist or developer is not thinking about the experience of the players. In the ludonarrative toolbox they 
may think about categorisations of player ability with player control, but not the actual experience during the game. It is because of focus on the game as object that the approaches are, I argue, less likely to impact practice. Both game designers and game writers know there are settings and characters, but knowing this and talking about it doesn't necessarily aid their creative process or mutual understanding. Transmodal approaches make sense on the face of it (I too have put my theories forward), but they ultimately don't do enough bridge work to break us out of our respective silos. I find that design schema tensions persist when we think about games, and films, and books, as isolated objects. These tensions can be avoided through resituating our focus away from what we make, to who we make for.

\section{From First-Order to Third-Order Design}

To explain the shift to a player/audience-centered approach, I draw on what design researcher Richard Buchanan describes as the orders of design (Buchanan 1998). For Buchanan, how we perceive the "product" we design changes over time. In the first half of the twentieth century, for instance, we focused on "symbols," and this correlated with the discipline of graphic design. To Buchanan, this is called "first-order design". (Buchanan 2001) We then moved to understanding "things" with industrial design, which is "second-order design." And then in the mid-1990s we shifted to designing "activity" with interaction design, which is "third-order design"; and then "thought" with environmental design ("fourth order design") — which includes the greater system involved in "products." These orders represent stages of design influenced by the context of their times, but they also represent perspectives that can persist no matter what the era.

What we see in the external design grammars of narrative (e.g.: The Hero's Journey); the transmodal lens of characters, settings, events, and props; and the ludonarrative toolkit of semantic differentials, is an emphasis on first and second-order design. They all focus on the object, 


\section{ToDiGRA}

the symbols, and things, and not the activity — what players do. But note, both non-games and games approaches have this mental model of first and second-order design (it isn't just non-interactive folk). However, focusing on the object has consequences. As the late Brian Clark niggled in his influential talk on phenomenology: we're "craftsmanship" and "object addicts" who love to talk about the "details and intricacies" of objects, not realising that objects only exist when we interact with them. (Clark 2013).

Golding, too, argues that the repercussion of the configuration definition of games is that "it carries with it assumptions and preconceptions that emphasize formal and textual processes to the detriment of experiential factors and the act of play." (Golding 2013, 37) Likewise, game researchers Jussi Kuittinen and Jussi Holopainen analysed key game design books and compared them to key design theories. In conclusion, they found the game design books focus on the object of design:

"Judging from the selection of the game design literature we analysed, game design is heavily governed by the object of the design, games. Although this may seem like an overly obvious statement, it carries with itself the connotation that the activity called design, is left to too little attention. Whereas the books concentrate on teaching the reader the principles and elements of game design, at the same time they leave aspects of design activity such as representing, moving and reflecting to little consideration." (Kuittinen and Holopainen 2009, 7)

What does this mean? By focusing on the game as object, scholars and practitioners have focused on the characteristics of the game: its features, mechanics, characters, setting, UI, and so on. But in many areas of practice things have developed in a different direction. In his study on the design processes of AAA videogames, for instance, Ulf Hagen found a disparity between what game development handbooks and textbooks taught was an outcome of the first phase of development - the game design document (GDD) - and what is actually happening in AAA studios. (Hagen 2012) 
These studios are moving away from Big Design Up Front (BDUF) and Waterfall development (Royce 1970), where conception needs to be completed and is a locked blueprint for production. Instead, Hagen explains, there is "a new paradigm in game development" that has emerged, that differentiates itself from the traditional method of creating games. (Hagen 2012, 75) The new paradigm includes a focus on player experience rather than features; and on agile development methods such as the integration of design and implementation. In other words, thirdorder design; which as Buchanan foretold, "[w]e are now in the early formative stage of understanding how third and fourth-order design will transform the design professions and design education.” (Buchanan 2001, 12) Third-order design is what connects the artforms; we all have people that experience our projects, and we make better work when we consider them as part of the creation process. That doesn't mean moving production, prototyping and testing earlier, as Katherine Neil warns that this leaning on early prototyping can be damaging (Neil 2016). By bringing the execution stage in earlier, we are robbing ourselves of important design reflection: "our creative process [is] held hostage by the oftentimes alienating and frantic churn of the production and testing cycle.” Instead, what we can do is develop design schemas that acknowledge the experience of our work at all stages of development. So how can narrative design work with third-order design, and why is it effective?

\section{STORY AND GAME MEET CUTE: A PLAYER-CENTERED SCHEMA}

The following outlines three proposals that avoid design schema tension. One is a tweaking of an existing framework (MDA) that will aid in reframing games as narrative-inclusive phenomena for educators. The next is an already-proven model from screenwriting (sequence questions) that refocuses narrative structure as an audience/playeroriented approach. The final proposal is drawn from education 
40 ToDiGRA

(transformational learning) that re-situates the hero's journey as a player transformation structure.

\section{From MDA to EBE}

One of the models most commonly utilised to teach game design is the "MDA framework". (Hunicke et al. 2004) MDA, synonym of Mechanics, Dynamics and Aesthetics, was introduced as "a formal approach to understanding games - one which attempts to bridge the gap between game design and development, game criticism, and technical game research.” The authors sought to offer a framework that represents game artifacts not as fixed objects like movies or books, but "as systems that build behaviour via interaction." Indeed, over a decade ago, they succeeded in offering a framework that entwines both a "consumption perspective" and design. The lenses are described as follows:

"Mechanics describes the particular components of the game, at the level of data representation and algorithms. Dynamics describes the run-time behavior of the mechanics acting on player inputs and each other's outputs over time. Aesthetics describes the desirable emotional responses evoked in the player, when she interacts with the game system."

An example they offer is a babysitting game where perhaps you are trying to find a baby and get them to sleep. The aesthetics could be exploration and discovery, the dynamics would not be about competition but instead about getting the baby to express emotions like surprise and fear, and the mechanics can be talking to the baby, chasing the baby, and sneaking. The framework is immensely helpful in getting game development students to think beyond their player-perspective of games as rules and winning. It includes their player strategies (how to lure the baby out for instance), but also how those strategies were facilitated by the mechanics, and then how it made the player feel. 
However, there are two issues that have led me to make some changes to the language used. I feel the framework does address these in spirit and intention, but the actual wording can cause some confusion. The first is the last word: "aesthetics". The sense that it is used in this framework does not correspond with the usage taught to students through art history, design, and psychology. So I have instead used the word "experience". The second is the second word: "dynamics". I have chosen to use the term "behaviours" to emphasise that it is how the player then acts within in the videogame or in their interpersonal interactions with live players. The last word I've changed is specific to the point of this article: "mechanics" to "elements". When we talk about the ways we can influence the player, we don't want designers to fixate on mechanics being the only communicative act. We can influence them through the emotional design of the Playable Character (PC)-Non-Playable Character (NPC), NPC-NPC, and PC-PC relationships; through music and sound effects; inputs and physical devices; through art, lighting, and anticipatory play (Upton 2015a). Indeed, as Upton explains on the problems with focusing on mechanics:

"One of the drawbacks of associating games so closely with interactivity is that it biases design away from stillness. It encourages the construction of games that are action-packed, with lots of short-term business for the player to attend to. But if the moment-to-moment demands of immediate play are too pressing, we may never have the mental space for longer arcs of internal play. It's hard to plan your getaway in the middle of a gunfight, even if planning your getaway would be fun. And it's hard to think about the deeper meaning of a play experience if your entire attention is required merely to sustain it." (ibid., 78)

Through the slight tweaking of MDA (mechanics, dynamics, aesthetics) to EBE (elements, behaviours, experience), I find I can steer students into a direction that avoids design schema tension. They are open to games being more than mechanics, and so narrative is not viewed as a wrapper. I still give students the pivotal MDA paper, but just offer a quick personalisation of the terms. So, this is one approach. The next two structures are offered not just to educators but also developers (which can be the same person of course). Let's address Aristotle and Acts. 


\section{From Three Acts to Sequence Questions}

The notion of a three-act structure is helpful to film, TV, and games if we draw on its core principles of a beginning, middle and end. Any experience has these traits for an audience or player. What does not translate well are the specifics of what happens in the beginning, middle, and end. In filmmaking for instance, there are usually set events that are meant to happen at exact page numbers (which correlate to time on screen). Games have different run times and what constitutes the beginning, middle and end is not as clear cut and is not helpful to minuteby-minute design. Indeed game writers Richard Rouse III and Tom Abernathy have criticised the three-act structure because most players do not finish games, and because (citing Microsoft's research by Hendersen 2014) players do not remember plot elements anyway (Rouse and Abernathy 2014).1 But there is an approach to structure that is utilised in screenwriting and works exceptionally well with games. It is one that switches the emphasis away from plot points to what people experiencing the game are thinking. I am talking here of "sequence questions".

While the concept of sequences has antecedents in the 1800s, it was championed by film director, producer, writer and educator Frank Daniel in the 1970s and 1980s. He researched successful screenplays and discovered they all shared this trait. Then through his role as the head of the Graduate Screenwriting Program at USC, he designed a curriculum around the sequence method. Paul Joseph Gulino then popularised Daniel's approach in the now key text: Screenwriting: The Sequence Approach (Guilino 2004). The sequence approach is observable in many great films: Being John Malkovich, Double Indemnity, The Fellowship of the Ring, The Graduate, North By Northwest, One Flew Over the Cuckoo's Nest, Toy Story. But as explained in the forward to Gulino's book, “... unlike other popular approaches to screenwriting, the sequence method focuses on how the audience will experience the story and what the writer can do to make that experience better.” (Marlowe in ibid., xiii) 
With its emphasis on the audience experience, the sequence approach is part of the mental model that correlates with best practice in game design. How? Sequencing divides the experience into a series of questions for the audience to consider. There is the overall question introduced at the beginning and answered near the end, and then multiple short-term questions to keep driving the audience's interest. As Gulino explains, the series of dramatic questions sequences "offer the opportunity to give the audience a glimpse of a great many possible outcomes to the picture before the actual resolution.” (Guilino 2004, 13) They wonder what possible outcome could happen and hope or act towards it. In his book The TV Showrunner's Roadmap, Neil Landau talks about the critical element of the central question in a TV series:

"A good central question stokes the audience's curiosity and their need to know more. How is this problem going to be solved? What's going to happen? [NP] All great TV series present us with strong central questions. [...] Central questions are the key ingredient of "must-see TV". We're waiting to see how the crime story or a love story is going to play out. As long as we keep wondering and anticipating and discussing and posting-we're going to keep watching. As soon as all questions are answered, the series is forced to either introduce new central questions or end." (Landau 2013, 31)

This notion of a question driving the audience is not unique to screenwriting, it has been observed in novel writing. Philosopher Noël Carroll studied philosopher David Hume and his discussions of best practice:

"Hume observes that a very effective technique of narration involves presenting the reader, viewer, or listener with a chain of events about whose outcome she is enticed into becoming curious-about which she wants to know "what happens next?-but, then to hold off telling her." (Carroll 2007, 3)

Carroll continues to describe how questions drive the experience for the audience. They do not experience closure until all questions are answered. For instance, will X marry Y? or will X kill Y? Feature film developer Stephen Cleary explains further how the sequence question 
operates and how it always needs to be about external plot and not internal movements (Apocalypse Films, 2015). He argues that screenwriters need to focus on action more than character, more on how your audience feels rather than how your character feels. Without doubt, there are correlations with the design of games here, where the designer needs to think about what the player's objective is and how they will understand what it is and how they will learn how to do it. Indeed, Carroll also entertains the idea of questions and answers becoming problems and solutions (Carroll 2007, 7). Sequence questions, then, are always from the perspective of the audience and grounded in the actions of the characters (what characters do). So, following the question structure of "will $\mathrm{X}$ verb $\mathrm{Y}$ ?" in games, we could have the player question "how can I X?" How can I get to the other side of the chasm? How can I jump higher? How can I avoid the tumbling rocks? How can I move that box? With sequence questions, we have a method that allows writers and designers to speak the same language and have the same design goal: the experience of the player.

Indeed, Robert Denton Bryant and Keith Giglio, who have worked on screenplays and games, refer to the sequence approach in their 2015 book, Slay the Dragon: Writing Great Video Games, and draw a parallel between the structure of sequence mini-objectives and objectives in level design (Bryant and Giglio 2015, 99). And in 2013, Jeremy Bernstein, who also writes across film, TV and games (such as TNT's The Librarians and EA's Dead Space 2), gave a talk at the Game Developers Conference on how sequence structure works better for games because it is objective driven and works with gameplay loops (Bernstein 2013). These creators, who champion the sequence method, it should be noted, have internal design grammars with both games and film/TV. This means they have had to deal with the cognitive load of disparate schemas, and worked to reduce the tension. Here we have a structural method with no schema tension that represents best practice for games, films, TV shows, and literature. What of the "hero's journey" then, and how this can be developed for third-order design? 


\section{From Hero's Journey to Transformational Learning}

With sequence questions we have a method used in film and TV that is about audience and player actions: what they think may happen and what they need to happen. In this section we look at how the player and audience member can be changed by the experience. We move from their objectives to their worldviews. The pervasive structure in screenwriting is The Hero's Journey. You're told that there must a hero that declines the call to help others, and then goes through a series of tests and so on. But let's be clear about what this journey is. It is a journey based on stories from the past, stories written in a different cultural context where a male hero who was "tempted by a seductress" was accepted as being applicable to all. Other practitioners and theorists have criticised such nuances, such as the recent proposal by transmedia professional Jeff Gomez for a “collective journey” rather than a "hero’s journey”:

"Story, he says, no longer needs to be linear. It no longer requires the polarization of good and evil; the kind of violence and single-minded righteousness that gave the model such a "masculine impulse," as he calls it.” (Gomez in Staffans 2017)

The structure still has utility, but for actually transforming a player now (who may be of any gender and not need to think in terms of conflict) it is not as effective. Indeed, while the flipping of the hero as the player is an attempt to translate the structure to games, it isn't as effective because players do not experience the journey in that way. Not all players would want to deny the call for help, for instance. It needs to be adapted to work. Watching (and empathising with) a character transform is not the same as being transformed yourself. In games (and other interactive projects), this is the critical design question: how can I change someone's mind? How can I get them to understand something? Teach them a new skill? Get them to feel something? What is needed is something that moves the player through an internal journey. How? One answer to this question is in education. 
It should be no surprise that an educational model can work for games. As Gee has explained, "[g]ood games [...] are crafted in ways that encourage and facilitate active and critical learning and thinking." (Gee 2003, 46) The idea of education and games may, though, still be thought of as applying only to certain games: for transformational games where the design is focused on the player being changed in a way that persists after the game. Indeed, while this easily falls within the remit of serious games, any games can be included. As Sabrina Haskell Culyba, Senior Designer at Schell Games, explains in A Field Guide for Design Leaders on Transformational Games, transformation comes in many forms: knowledge, skill, physical, disposition, behaviour, belief, relationships, and identity (Culyba 2015). Now, it should be noted there are other helpful structures out there used for player transformation, like designer Erin Hoffman's "sophia” process where "fun" and learning can be understood as a "cognitive mechanical process by which we convert fear to happiness through surprise.” (Hoffman 2015) But here I want to draw attention to a particular model of 'transformational learning' that emerged a few decades ago.

Transformational learning refers to a pedagogical approach that facilitates a worldview change. It came about in the 1970s when adultlearning educator Jack Mezirow was working with women who were returning to study after a major life event such as divorce, or a death in the family. Their lives were completely changed, and over time he recognised a pattern in how a transformation takes place, and documented the principles (Mezirow 1978). This approach has since been developed by Mezirow and numerous others in schools, PhDs, books, and conferences. Dr. Patricia Cranton, for instance, describes transformational learning as a process where:

"[A]n individual becomes aware of holding a limiting or distorted view. If the individual critically examines this view, opens herself to alternatives, and consequently changes the way she sees things, she has transformed some part of how she makes meaning out of the world." (Cranton n.d.) 
How can this notion be employed as a structure? After decades of research into effective pedagogical approaches, there are what are considered the "phases of transformational learning” (Mezirow 2006):

1. A disoriented dilemma;

2. Self-examination with feelings of fear, anger, guilt or shame;

3. A critical assessment of assumptions;

4. Recognition that one's discontent and the process of transformation are shared;

5. Exploration of options for new roles, relationships and action;

6. Planning a new course of action;

7. Acquiring knowledge and skills for implementing one’s plans;

8. Provisional trying of new roles;

9. Building competence and self-confidence in new roles and relationships;

10. A reintegration into one's life on the basis of conditions dictated by one's new perspective.

A "disorienting dilemma" is externally-imposed through the death of a loved one, divorce, job change, retirement, or relationship breakup. But it can be facilitated through an eye-opening discussion, or creative project. For us, it is a catalyst at the beginning of the game. We're used to writing a catalytic event for a protagonist, but we need it for the player. In this structure, our catalytic event asks the player to question themselves and the way they've seen the world in a particular way:

"Anomalies and dilemmas of which old ways of knowing cannot make sense become catalysts or 'trigger events' that precipitate critical reflection and transformations. Changing social norms can make it much easier to encounter, entertain, and sustain changes in alternative perspectives." (Mezirow 1990, n.p.)

This leads to a "reassessing [of] our own orientation to perceiving, knowing, believing, feeling and acting." (ibid.) Many games offer a confrontation of assumptions, but those assumptions are based on our interpretation of the game. The unreliable narrator of The Stanley 


\section{ToDiGRA}

Parable (Galactic Cafe 2013), the twists in Bioshock (2K Boston and 2K Australia 2007), Spec Ops: The Line (Yager Development 2012), and Assassin's Creed (Ubisoft 2007-present). Interestingly, if we consider assumption flips that are not about the game but instead about the player, the disoriented dilemma often happens at the end of a game. Examples include: Braid (Number None, Inc. 2008) where we think we are the good guy saving a princess but it turns out this is not the case; and Chrono Trigger (Square 1995) where you are charged for actions you thought were normal. In this model, we need to enable a disorienting dilemma for the player, where their assumptions about how their own world works are confronted, at the beginning rather than later. For instance, you start playing a game representing a matriarchal society, and you find it disorientating because it feels so different. Depending on your culture, this may provoke questions about your own world.

This disorientation facilitates a self-examination of feelings (you need to have an emotional response) and assumptions. Some may argue that self-examination and assumption reflections have no place in games, as games are about interactivity or rules or winning (whatever identityforming definition differentiates the most). But as mentioned earlier, stillness is as much part of action games and so shouldn't be ignored as part of the design. Reflection happens already in games, but can be consciously introduced further. In his book Triadic Game Design (Harteveld 2015), Casper Harteveld relates how he designed for reflection in his serious game. There are two kinds of reflection: "reflection-on-action" (afterwards) and "reflection-in-action" (during), both of which are needed in transformational learning (Schön 1983). Harteveld found the former easy, but wanted to facilitate reflection during the game in a manner that didn't require pausing it. He came up with players having to give a "situation assessment" where they report to an NPC on whether a situation is not serious, serious, or very serious (which forces the player to think about and categorise the experience) (Harteveld 2015, 248). 
The process of self-examination and developing a new way of thinking, then, also involves understanding "intellectually and empathetically, the frame of reference of the other." (Mezirow 2006) This is facilitated, Mezirow explains, when we participate freely and fully in a discussion. For narrative designers, this can be with other players or NPCs, or delivering information through other means. Traits of a successful consideration of other points of view include having accurate and complete information, being open and empathic and withholding judgement, being able to understand and weigh evidence to assess arguments objectively, becoming aware of the context of ideas and assumptions, having equal opportunities to participate in various discourses, having a validity test that assists until new perspectives take hold, and being free of coercion. 2

If we keep following the structure, then there needs to be some way they can share their discontent with others, which may be other players or NPCs. This means ensuring there are ways to express emotion through movement or dialogue, for instance. The following steps - building confidence, new behaviours, planning, acquiring knowledge and skills, experimenting with roles, building competence - are all part of instructional design in games already. We have to teach players how to learn the skills or actions or system of the game in order to navigate and succeed in it. To do this we use instructional design techniques such as those outlined in Rudolf Kremers' book, Level Design: Concept, Theory, Practice, which include, teaching by doing, teaching by example, formal tuition (overt and covert), and teaching through experiment (Kremers 2009).

Looking over all the stages of transformation, there are some correlations with the hero's journey (see table below). The ordinary world may be represented in the game, or can be considered as the player's life before the game. Conversely, returning with the elixir is reflected in the player reintegrating what they've learned into their everyday life. As we can see, we have a model that is about the player journey. We just have to figure out how to affect each person directly, rather 


\section{ToDiGRA}

than making assumptions about what is disorienting for all. There are other approaches to be explored as the overlap between game design and learning design becomes more widely recognised and utilised by designers and educators alike (Toppo 2015). But what we have here is the guiding principle of the player/audience as the focus of the journey, drawn from an already successful model of human change in adult education.

\begin{tabular}{ll}
\hline $\begin{array}{l}\text { Hero's Journey (Vogler) } \\
\text { The Ordinary World }\end{array}$ & $\begin{array}{l}\text { Transformative Learning (Mezirow) } \\
\text { [Player's ordinary world before you enter the game] }\end{array}$ \\
$\begin{array}{l}\text { The Call to Adventure } \\
\text { Refusal of the Call }\end{array}$ & $\begin{array}{l}\text { Disorienting Dilemma } \\
\text { Self-examination }\end{array}$ \\
Meeting with the Mentor & Assessment of Assumptions \\
Crossing the Threshold & Relating Discontent to Others \\
Tests, Allies, Enemies & Explaining Options of New Behaviour \\
Approaching the Cave & Building Confidence in New Ways \\
The Ordeal & Planning a Course of Action \\
The Reward & Acquiring Knowledge and Skills \\
The Road Back & Experimenting with New Roles \\
Resurrection & \\
Returning with the Elixir & Reintegration (into player's everyday life) \\
\hline
\end{tabular}

Table 1: Juxtaposition of Hero's Journey (Vogler) and Transformational Learning Structures (Mezirow).

\section{CONCLUSION}

The inciting issue of this article has been that games currently suffer from a narrative and game binarism that repels gestalt. It was offered that this binarism is an artificial construction rather than an irreconcilable trait. Through the notion of a design schema, it was explained that that binarism comes from how games and narratives are framed to us through professional discourse and education. These design schemas 
produce a tension because they are the result of a rampant differentiation rhetoric that draws a thick line between what games and narratives are. Subsequently, developers have what is recognised as an external design grammar of narrative. So, narrative design schemas have to be imported from other disciplines, following what is well-known rather than what is the most effective (the two are not always the same).

We then looked at some of the attempts to address this design schism with the narrative designer role, transmodal and common traits approaches. However, it was argued that by relegating the task of integration to a person, and focusing on the elements of a game object, developers are still left with no concept of narratives and games, as distinct phenomena. A switch to focusing on the audience or player was argued to be the key to finding a common base that avoids design schema tension and facilitates best practice. Explaining this through the existing notion of orders of design, it was shown that third-order design is where the activity of the audience or player are part of the mental model of creation representing contemporary design practice.

Finally, three solutions to address the problem of design schema tension are offered. The first was the tweaking of the MDA (mechanics, dynamics, aesthetics) framework to be consciously inclusive of nongame elements and less ambiguity and multidisciplinary confusion with the use of EBE (elements, behaviours, experience) terms. The second is the replacement of the notion of plot points in narrative arcs, with the successful Hollywood approach, audience-oriented sequence questions. The third and final proposal was to provide a structure that replaces the hero's journey with transformational learning phases from education.

The audience/player-centric schema was proposed to be an approach that will avoid design schema tension, and facilitate better games. It will aid the work of narrative designers, writers, and designers. It also assists transmedia writers and designers who work on games and films, TV shows, and books, as we've seen an increase with productions like Halo (Bunge 2001-present), Assassin's Creed (Ubisoft 2007-present), Angry 


\section{ToDiGRA}

Birds (Rovio Entertainment 2009-present), and indies like Firewatch (Campo Santo 2016-present) and Life is Strange (Dontnod Entertainment 2015-present) for example. It means they can use the same design schemas across productions.

I am interested in seeing how the player transformation structure can be developed, discovering more models. I can see congruences with Hoffman's emotional arc for learning mentioned earlier, and encourage educators to resituate how they teach narrative to games students to avoid creating another generation of design schema tension.

It is hoped that the outcome of this article is a consideration of the critical damage an exclusionary approach (where one artform needs to be differentiated to be identified) has as it defers understanding of what makes any artform great: its affect on others. Differentiation tactics are good at short-term identity-forming, but terrible at attracting experts from other areas (as points of similarity are downplayed or rejected), community building (as there is a limit to how many different approaches/people are welcome) and ultimately making good work (as it precludes cumulative insight).

The ultimate point is not that a player-centric approach is the pinnacle of design schemas. There will be and are other epiphanies of practice. The point is not to simply shift to new structures. Creatives use whatever tools work for them. Instead, the point is to be open to changing for the better. How do we do that? A helpful guide may be whether the insight brings us closer together or further apart. That doesn't equate to choosing to be the same or different. It is about honouring what both unites and differentiates us, not just the latter. And the most obvious connection between all artforms is who is experiencing our work.

\section{NOTES}

1. For Rouse and Abernathy, that last point is particularly telling: players remember characters not plot and so we should not worry 
about plot. Character certainly is critical, but players and playtesters have narrative and game schemas that obscure insight too. What if, for instance, players were asked to retell the decisions they made? Would we see the retelling of the plot emerge?

1. On this last point, let us note Tiltfactor's research into "embedded games" where they found obfuscating the serious game “circumvents players' psychological defenses" and "triggers a more receptive mindset for internalizing a game's intended message.” (Kaufman, Flanagan, and Seidman 2015) Perhaps, therefore, not announcing the serious game nature of a project enables the player to feel less coercion?

$\mathrm{BIO}$

Dr. Christy Dena is Senior Lecturer of Games at SAE Creative Media Institute, and owner of Universe Creation 101 where she is a designerwriter-director of apps, card and live games. She has been the Chair of Games for Australia and Dubai, and Chair and Department Coordinator of Games at SAE. She achieved her $\mathrm{PhD}$ in Transmedia Practice at Sydney University, Postgraduate Diploma in Creative Writing at Melbourne University, and Bachelor of Arts in Visual \& Performing Arts at Monash University. Christy has lectured around the world, been published in numerous books, and runs an international professional lab for creatives working on the fringes: Forward Slash Story. Christy's projects have won, and have been, nominated for multiple awards, including winning the AWG Award for Interactive Media, WA Premier's Book Award for Digital Narrative.

\section{ACKNOWLEDGMENTS}

Thank you to the reviewers of this article, and my journal co-editor Brendan Keogh. 
54 ToDiGRA

BIBLIOGRAPHY

2K Boston and 2K Australia. Bioshock [Xbox 360, Xbox One, PS3, PS4] 2K Games, 2007. Played 2009.

Aarseth, E. Cybertext: Perspectives on Ergodic Literature. Baltimore, MD: Johns Hopkins University Press, 1997.

Aristotle. Poetics. New York, USA: Dover Publications, 1997 [330BC].

Bartlett, F. Remembering: A Study in Experimental and Social Psychology. London, UK: Cambridge University Press, 1932.

Bernstein, J. "Reimagining Story Structure: Moving Beyond Three Acts in Narrative Design.” Presented at Game Developers Conference, 2013. http://www.gdcvault.com/play/1019750/Reimagining-Story-StructureMoving-Beyond.

Buchanan, R. "Branzi’s Dilemma: Design in Contemporary Culture" Design Issues 14, no. 1, 1998: 3-20.

Buchanan, R. "Design Research and the New Learning” Design Issues 17, no. 4 , 2001: 3-20. Bunge/343 Industries. Halo [Xbox, OSX, Windows Phone, iOS, Xbox One, Novels, Short Film, Feature film, ARG]. Microsoft Studios, 2001-present.

Bryant, R.D. and K. Giglio. Slay the Dragon: Writing Great Video Games. Studio City, USA: Michae Wiese Productions, 2015.

Campbell, J. The Hero with a Thousand Faces. Novato, USA: New World Library, 2012 [1947].

Campo Santo. Firewatch [PS4, Xbox, PC, forthcoming Feature Film] Panic and Campo Santo, 2016-present.

Carroll, N. “Narrative Closure” Philosophical Studies 135, 2007: 1-15. 
Chen, J. "Designing Journey." Presented at Game Developers Conference, 2013. http://www.gdcvault.com/play/1017700/Designing.

Clark, B. “Are YOU Phenomenal?” Presented at DIYDAYS, 2013. https://www.youtube.com/watch?v=fNcMnV9DGh0.

Cranton, P. "Getting To Know Transformative Learning Theory." Transformative Learning. Accessed March 1, 2016. http://www.transformativelearning.org/index_files/

Getting\%20to\%20know\%20Tra nsformative\%20Learning\%20Theory.pdf, n.d.

Cross, N. Engineering Design Methods: Strategies for Product Design 4th Ed. Chichester, UK: John Wiley, 2008.

Crystal Dynamics. “Narrative Designer.” Jobvite. Accessed October 30, $2016 . \quad$ http://app.jobvite.com/CompanyJobs/ Careers.aspx?k=Job\&c=qpa9Vfwn\&j=oVfl3fwi\&s=Indeed, 2016.

Culyba, S. H. "A Field Guide for Design Leaders on Transformational Games.” SlideShare. Accessed March 1, 2016. http://www.slideshare.net/SeriousGamesAssoc/sabrina-haskell-culyba, 2015.

Dansky, R. "Screw Narrative Wrappers.” Gamasutra. Accessed March 1, 2016. http://www.gamasutra.com/blogs/RichardDansky/20140623/ 219615/Screw_Narrative_WrappErs.php, 2014.

Dena, C. "Transmedia Practice: Theorising the Practice of Expressing a Fictional World Across Distinct Media and Environments" (PhD diss., University of Sydney, 2009) Dontnod Entertainment. Life is Strange [PC, PS3, PS4, Xbox 360, Xbox One, forthcoming Feature Film]. Square Enix, Feral Interactive, 2015-present. Played October 2016.

Eskelinen, M. “The Gaming Situation.” Game Studies 1, no.1: 2001. 
56 ToDiGRA

Eskelinen, M. "Explorations in Game Ecology, Part 1." Forum Computerphilologie. Accessed March 1, 2016. http://computerphilologie.uni-muenchen.de/jg05/eskelinen.html, 2005.

Fingleton, T., Dena, C. and J. Wilson. The Writer's Guide to Making a Digital Living: Choose Your Own Adventure. Sydney, AUS: Australia Council for the Arts, 2008.

Frasca, G. "Ludology Meets Narratology: Similitude and Differences Between (Video)games and Narrative.” Ludology. Accessed March 1, 2016. http://www.ludology.org/articles/ludology.htm, 1999.

Frasca, G. "Simulation versus Narrative: Introduction to Ludology." In The Video Game Theory Reader, edited by M. J. P. Wolf and B. Perron, pp. 221-236. Oxford, UK: Routledge, 2003.

Freeman, D. Creating Emotion in Games. Berkeley, USA: New Riders Publishing, 2004.

Fullerton, T. Game Design Workshop: A Playcentric Approach to Creating Innovative Games.MA, USA: Morgan Kauffman, 2008.

Galactic Cafe. The Stanley Parable [PC] Galactic Cafe, 2013. Played Dec, 2013.

Gameloft. "Narrative Designer.” Creative Heads. Accessed October 30, 2016. http://www.creativeheads.net/job/12859/narrative-designer-intoronto, 2016.

Gee, J.P. What Video Games Have to Teach Us about Learning and Literacy. New York, USA: Palgrave Macmillan, 2003.

GlassLab. "GlassLab Game Design Handbook.” GlassLab Games. Accessed March 1, 2016.http://gamedesign.glasslabgames.org/, 2016. 
Golding, D. "To Configure or to Navigate?: On Textual Frames.” In Terms ofPlay: Essays on Words That Matter in Videogame Theory, edited by Z. Waggoner. Jefferson, USA: McFarland \& Company Inc, 2013.

Gulino, P. J. Screenwriting: The Sequence Approach. New York, USA: Continuum International Publishing Group Inc., 2004.

Hagen, U. "Lodestars for Player Experience: Ideation in Videogame Design.” (Licentiate Thesis, Stockholm University, 2012).

Hamari, J. \& Tuunanen, J. "Player Types: A Meta-Synthesis" Transactions of the Digital Games Research Association 1, no. 2, 2014: 29-53.

Hartmann, T. \& Klimmt, C. "Gender and Computer Games: Exploring Females' Dislikes” Journal of Computer-Mediated Communication 11, no. 4, 2006: 910-931.

Hendersen, D. "Using User Research to Improve Game Narratives." Presented at Game Narrative Summit, Game Developers Conference, 2014. http://www.gdcvault.com/play/1020031/Using-User-Research-toImprove.

Hocking, C. "Ludonarrative Dissonance and Bioshock.” Click Nothing. Accessed March 1 2016.http://clicknothing.typepad.com/click_nothing/ 2007/10/ludonarrative-d.html, 2007.

Hoffman, E. "Wind, Not Sand: Mapping Dynamic Emotion Across a Product Landscape.” Presented at UX Week, San Francisco, CA, 2015. https://vimeo.com/139025674.

Howard, T. "Why We Play, Why We Create.” Presented at DICE Summit, 2012. http://www.dicesummit.org/video_gallery/ 2012_video_gallery.asp.

Hunicke, R., LeBlanc, M., and R. Zubek. "MDA: A Formal Approach to Game Design andGame Research." In Proceedings of the $A A A I$ 


\section{ToDiGRA}

Workshop on Challenges in Game AI 4. http://www.aaai.org/Papers/ Workshops/2004/WS-04-04/WS04-04-001.pdf, 2004.

Juul, J. “Games Telling Stories?: A Brief Note on Games and Narratives” Games Studies 1, no. 1, 2001. http://www.gamestudies.org/0101/juulgts/.

Kallio, K. P., Mäyrä, F. \& Kaipainen, K. “At Least Nine Ways to Play: Approaching Gamer Mentalities” Games and Culture 6, no. 4, 2011: 327-353.

Kaufman, G., Flanagan, M., and Seidman, M. "Creating Stealth Game Interventions for Attitude and Behavior Change: An 'Embedded Design' Model.” In Proceedings of DiGRA International Conference 2015. http://www.digra.org/digital-library/publications/creating-stealthgame-interventions-for-attitude-and-behavior-change-an-embeddeddesign-model/.

Koenitz, H., Ferri, G., Haahr, M., Sezen, D., and T. Ibrahim Sezen. “Towards a Ludonarrative Toolbox." Presented at DiGRA 2015, Lüneburg, Germany.

Kuittinen, J. and J. Holopainen. "Some Notes on the Nature of Game Design.” In Proceedings ofDiGRA 2009. http://www.digra.org/wpcontent/uploads/digital-library/09287.49313.pdf.

Lakoff, G. and M. Johnson. "The Coherent Structuring of Experience.” In Metaphors We Live By, pp. 77-86. Chicago, USA: The University of Chicago Press, 1980.

Landau, N. The TV Showrunner's Roadmap: 21 Navigational Tips for Screenwriters to Create and Sustain a Hit TV Series. Boca Raton, USA: CRC Press, 2013.

Lazarro, N. "Why we Play Games: Four Keys to Emotion without Story”. XEO Design. Accessed March 1, 2016. http://www.xeodesign.com/whyweplaygames/ xeodesign_whyweplaygames.pdf, 2004. 
Lindley, C. A. and C. C. Sennersten. "A Cognitive Framework for the Analysis of Game Play: Tasks, Schemas and Attention Theory.” In Proceedings of Conference of the Cognitive Science Society: Workshop on the Cognitive Science of Games and Game Play, Vancouver, Canada, 2006.

Lotman, Y. Universe of the Mind: a Semiotic Theory of Culture. Bloomington, USA: Indiana University Press, 1990.

Marras, S. Screenwriting: History, Theory and Practice. London, UK: Wallflower Press, 1990.

Mezirow, J. "Perspective Transformation.” Adult Education Quarterly 28, no. 2, 1978: 100- 110.

Mezirow, J. How Critical Reflection Triggers Transformative Learning. In Fostering Critical Reflection in Adulthood, edited by J. Mezirow, pp 1-20. San Francisco: Jossey-Bass Publishers, 1990.

Mezirow, J. An Overview of Transformative Learning. In Lifelong Learning: Concepts and Contexts, edited by P. Sutherland \& J. Crowther, pp: 24-38. New York \& London: Routledge, 2006.

Murray. J. "Not Film and Not an Empathy Machine.” Immerse. Accessed October 10，2016. https://immerse.news/not-a-film-and-not-anempathy-machine-48b63b0eda93\#.1pnf1yk9m, 2016.

Neil, K. (2016) “How We Design Games Now and Why.” Haikus by KN. Accessed December 11, 2016. https://medium.com/@haikus_by_KN/ how-we-design-games-now-and-why-bcbc1deb7559\#.vmhythpau. First published in Critical Hits: An Indie Gaming Anthology, edited by Z. Jellicoe. Dublin, Ireland: Sunday Books, 2016.

Norman, D. The Design of Everyday Things. Philadelphia, USA: Basic Books, 2013 [1998]. 
60 ToDiGRA

Number None, Inc. Braid [Xbox 360, PS3, PC] Number None, Inc. and Microsoft Game Studios, 2008.

Obsidian Entertainment. "Narrative Designer.” Obsidian.net. Accessed October 30, 2016. http://www.obsidian.net/jobs/open-positions/design/ 936-narrative-designer, 2016.

Rollings, A. and E. Adams. On Game Design. Indiana, USA: New Riders, 2003.

Rovio Entertainment. Angry Birds [iOS, Android, TV Series, Feature Film, Cookbook, Activity Book, Story Books, Theme Parks]. Rovio Entertainment, 2009-present.

Royce, W. "Managing the Development of Large Software Systems.” In Proceedings of IEEE WESCON 26, 1970: pp. 1-9.

Ryan, M.-L. Avatars of Story. Minneapolis, USA: University of Minnesota Press, 2006.

Salen, K. and E. Zimmerman. Rules of Play: Game Design Fundamentals. Cambridge, USA: MIT Press, 2003.

Schell, J. The Art of Game Design: A Book of Lenses. MA, USA: Morgan Kaufmann, 2010.

Schön, D. A. The Reflective Practitioner: How Professionals Think in Action. New York, USA: Basic Books, 1983.

Staffans, S. "Grappling with the Collective Journey." Simon Staffans. Accessed January 23, 2017. https://simonstaffans.com/2017/01/23/ grappling-with-the-collective-journey/, 2017.

Square. Chrono Trigger [SNES, PS1, NDS] Square and Square Enix, 1995. 
Suellentrop, C. "Inside the Making of 'BioShock' Series With Creator Ken Levine.” Rolling Stone. Accessed March 30, 2016. gttp://www.rollingstone.com/culture/news/we-were-all-miserableinside-bioshock-video-game-franchise-w439921, 2016.

Supermassive Games. "Narrative Designer." LinkedIn. Accessed January 30, 2017. https://www.linkedin.com/jobs/view/247324538, 2017.

Sweller, J. "Cognitive Load Theory: Learning Difficulties and Instructional Design” Learningand Instruction 4, 1994: 295-312.

Toppo, G. The Game Believes in You. New York, USA: St Martin’s Press, 2015.

Ubisoft. Assassin's Creed [PS3, Xbox 360, PS4, Xbox One, Wii U, Nintendo DS, PS Portable, PS Vita, Short Films, Feature Film, Graphic Novels, Comics, Novels] Ubisoft, 2007-present.

Upton, B. The Aesthetics of Play. Cambridge, USA: MIT Press, 2015a.

Upton, B. "The Play of Stillness: Designing Experiential Play Spaces." Presented Game Developers Conference, $2015 \mathrm{~b}$. http://www.gdcvault.com/play/1022317/The-Play-of-Stillness-

Designing.

Vogler, C. The Writer's Journey. Seattle, USA: Michael Wiese Productions, 2007.

Yager Development. Spec Ops: The Line [PS3, Xbox 360] 2K Games, 2012. 